\title{
High corn oil and high extra virgin olive oil diets have different effects on the expression of differentiation-related genes in experimental mammary tumors
}

\author{
RAQUEL MORAL, MONTSERRAT SOLANAS, GEMMA GARCIA, LAURA GRAU, \\ ELENA VELA, RAQUEL ESCRICH and EDUARD ESCRICH \\ Department of Cell Biology, Physiology and Immunology, Medical Physiology Unit, \\ Medical School, Universitat Autònoma de Barcelona, 08193 Bellaterra, Barcelona, Spain
}

Received March 3, 2008; Accepted April 24, 2008

DOI: $10.3892 /$ or_00000025

\begin{abstract}
Dietary lipids can modify the clinical behavior and morphological features of experimental breast tumors. We previously demonstrated that a high corn oil diet has a tumor-enhancing effect in 7,12-dimethylbenz $(\alpha)$ anthracene (DMBA)-induced rat mammary adenocarcinomas, whereas a high olive oil diet acts as a negative modulator of carcinogenesis. In this study, we investigated whether these high fat diets modulate the expression of genes related to differentiation. Rats were induced with DMBA and fed a low fat diet, a high corn oil diet, a high olive oil diet, or both high fat diets. The expression levels of the mammary differentiation biomarkers $\alpha$-casein, $\beta$-casein and transferrin and of $\beta$-actin and its transporter zipcode binding protein 1 (ZBP1) were analyzed by Northern and/or Western blot in the mammary adenocarcinomas. The high fat diets did not induce changes in the expression of caseins, while transferrin expression was increased as a result of the high olive oil diet. $\beta$-actin mRNA levels were higher in the high fat diet groups, though no changes in the protein levels were observed. The expression of $\mathrm{ZBP} 1$, a protein reported as having a role in carcinogenesis, was significantly increased by the high corn oil diet. These results suggest that in this model caseins are not good biomarkers of the changes in tumor morphological differentiation conferred by the high fat diets. The modulation of transferrin and ZBP1 expression by the high olive oil and the high corn oil diets could be one of the mechanisms by which such diets have a different influence on mammary carcinogenesis.
\end{abstract}

Correspondence to: Dr Eduard Escrich, Department of Cell Biology, Physiology and Immunology, Medical Physiology Unit, Medical School, Universitat Autònoma de Barcelona, 08193 Bellaterra, Barcelona, Spain

E-mail: eduard.escrich@uab.es

Key words: dietary lipids, breast cancer, differentiation, casein, transferrin, $\beta$-actin, zipcode binding protein 1

\section{Introduction}

Breast cancer is one of the leading causes of mortatility in women world wide (1), though the mechanisms underlying mammary carcinogenesis are still largely unknown. Although the risk of cancer is multifactorial, environmental factors are a substantial contribution and diet plays a significant role (2). Among the numerous dietary compounds that have been related to cancer, dietary lipids have been revealed as significant ones. Epidemiological and especially experimental studies have established a relationship between dietary fat and breast cancer $(2,3)$. n-6 polyunsaturated fatty acids (PUFA), particularly linoleic acid (18:2n-6), have shown a stimulating effect on breast, colorectal and prostate cancers in animal models. Saturated fat, mainly from animal origin has demonstrated a tumor-enhancing effect. In contrast, high levels of n-3 PUFA, conjugated linoleic acid and $\gamma$-linolenic acid, have shown inhibitory effects on cancer (3-7). The role of monounsaturated fatty acids, such as oleic acid (18:1n-9), in cancer appears to be protective although some inconsistent results have been reported. The Mediterranean diet, whose hallmark is the high consumption of olive oil, has been traditionally linked as having a protective effect on cardiovascular disease and cancer $(7,8)$.

We previously demonstrated the influence of dietary lipids on the alteration of differentiation features in experimental breast cancer. In rat mammary tumors induced with 7,12-dimethylbenz $(\alpha)$ anthracene (DMBA), we observed that a high corn oil diet, rich in n-6 PUFA, confers a clinical behavior of higher malignancy and a lower degree of histopathological differentiation to the tumors, in comparison with a low fat diet. On the contrary, a high extra virgin olive oil diet would act as a negative modulator of the mammary carcinogenesis, conferring a lower degree of malignancy to the tumors in comparison to the control and high corn oil diets $(7,9,10)$. These changes were accompanied by modifications in the expression of genes that have been related to proliferation and differentiation. Thus, our group reported that the high n-6 diet and the high n-9 diet have different effects on the gene expression of the ErbB family of membrane receptors $(7,11)$. In addition, they do not modify the c-Ha-ras 1 mRNA levels though they had different effects 
on Ras activity $(7,12)$. Furthermore, we found that the high corn oil diet down-regulated genes that have been associated with differentiation, as submaxillary gland $\alpha-2 \mathrm{u}$ globulin, VDUP1 and H19 (13) and the PCPH gene, a proto-oncogene that acts synergistically with ras (14, unpublished data). PCPH had a higher expression in the lactating mammary gland than in the virgin gland and its expression was de-regulated in benign and malignant tumors (14). Thus, the high corn oil diet would induce modifications in the differentiation-related genes in accordance with its tumor-promoting effect, whereas the high olive oil diet induced changes on proliferation pathways compatible with its protective effect. All these previous results provided a rationale in studying the expression of differentiation biomarkers in the mammary gland, in order to further characterize the effects of the high fat diets on the differentiation features of the adenocarcinomas.

To assess the molecular differentiation of the mammary gland, several milk proteins have been frequently used. Some of the best known mammary differentiation biomarkers are caseins. Casein synthesis is a characteristic of differentiated mammary cells and their expression is decreased in adenocarcinomas (15). Transferrin has been considered as a mammary gland differentiation marker and its expression is greatly increased during pregnancy and lactation (16). The expression of $B$-casein and transferrin was down-regulated in the mammary glands of DMBA-induced rats (17), as well as underexpressed in mammary carcinomas induced with several carcinogens, including DMBA, in comparison to the normal tissue $(18,19)$.

The cytoskeletal protein $\beta$-actin has been used as an indicator of cellular differentiation in some experimental systems. The expression of $B$-actin was studied in hepatocyte cell lines, being inversely related to differentiation (20). Although $B$-actin is often used as a housekeeping gene to normalize mRNA levels in expression analysis, there is growing evidence that the expression of this gene is modulated in different physiological and pathological conditions. The expression of $\beta$-actin in tumor cells has been related to tumor invasive potential (21). The translation of $\beta$-actin is a spatial and temporal regulated process, which allows protein synthesis at specific sites of the cell. Localization of $\beta$-actin mRNA to sites of active actin polymerization modulates cell migration, thus playing a key role during embryogenesis, differentiation and carcinogenesis (21). Such localization requires zipcode binding protein 1 (ZBP1), a protein that binds to a conserved 54-nucleotide element in the 3'-untranslated region (UTR) of the $\beta$-actin mRNA and blocks the translation until ZBP1 releases the mRNA at the cell edge $(22,23)$. ZBP1 levels are high during fetal development, although they are low or undetectable in normal adult tissues. Moreover, ZBP1 has been suggested as a proto-oncogene, since its expression is reactivated in certain human cancers, including $60 \%$ of human breast cancers (24), therefore its de novo activation in tumors may be associated with the process of carcinogenesis (25).

To elucidate if a high corn oil and a high extra virgin olive oil diet changes the degree of molecular differentiation of DMBA-induced mammary tumors, in this study we examined the effect of such diets on the expression of known mammary differentiation markers, $\alpha$-casein, $\beta$-casein and transferrin. In addition, we investigated the mRNA and protein expression of $\beta$-actin, as well as the transporter protein ZBP1.

\section{Materials and methods}

Animals and experimental design. All of the animals received humane care under an institutionally approved experimental animal protocol, following the legislation applicable in Spain. Eighty virgin female Sprague-Dawley rats were purchased from Iffa-Credo (Lyon, France) at 22-days of age. Animals were housed four per cage and maintained in an air-conditioned room with a 12-h light/dark cycle. Rats were administered the control diet (containing 3\% corn oil) and water ad libitum until 53 days of age. At this age, animals were induced with a single dose of $5 \mathrm{mg}$ of 7,12-DMBA (Sigma-Aldrich, St. Louis, MO, USA) by oral gavage. Twenty-four hours after treatment, rats were randomly distributed into four groups $(n=20)$ depending on the diet subministered: the low fat group (LF) was maintained on the low fat control diet until the end of the study; the high fat corn oil group (HF-C) was administered the high fat diet containing $20 \%$ corn oil; the high fat olive oil group (HF-O) was given the high fat diet containing $3 \%$ corn oil and $17 \%$ extra virgin olive oil; and a forth group (HF-CO) in which rats were given the high corn oil diet for 5 weeks and then changed to the high olive oil diet until the end of the experiment (Table I). The definition, preparation and suitability of the experimental diets were previously described $(9,26,27)$. Animals were weighed, examined and palpated for mammary tumors once a week. On day 208 after induction rats were sacrificed by decapitation at the diestrus phase of the estral cycle. Tumors were rapidly removed, measured and rinsed in normal saline. Samples were flash-frozen in liquid nitrogen and stored at $-80^{\circ} \mathrm{C}$. Only confirmed mammary adenocarcinomas were included in this study.

Northern blot analysis. Total RNA was extracted from frozen mammary adenocarcinomas by the guanidinium isothiocyanate method. mRNA relative abundance was analyzed by chemiluminiscent Northern blot, as previously described (28). Briefly, $20 \mu \mathrm{g}$ of total RNA was electrophoresced on a formaldehyde-agarose gel, transferred onto positively-charged nylon membranes and hybridized with the specific probe labeled with digoxigenin by PCR (Roche Diagnostics GmbH, Mannheim, Germany). Probes for $\alpha$ - and $\beta$-casein were obtained as cultures of E. coli DH10B transformed with the correspondent I.M.A.G.E. Consortium Collection insert (clone Rn.10744 for $\alpha$-casein, clone Rn.10745 for $\beta$-casein) and amplified using the cDNA Primer GF-200 (ResGen, Invitrogen Corporation, Carlsbad, CA, USA). A 1150-bp mouse $B$-actin cDNA was kindly provided by Dr M. Buckingham (29) and a 756-bp rat p0 cDNA was kindly provided by Dr Y.L. Chan (30). Detection was performed using an alkaline phosphatase-coupled antidigoxigenin antibody (1:25000 dilution) and CSPD as a chemiluminescent substrate (Roche Diagnostics GmbH). Blots were exposed to Hyperfilm (GE Healthcare, Buckinghamshire, UK) and the autoradiograms were analyzed using Quantity One software (Bio-Rad Laboratories, Hercules, CA, USA). Ribosomal phosphoprotein P0 mRNA 


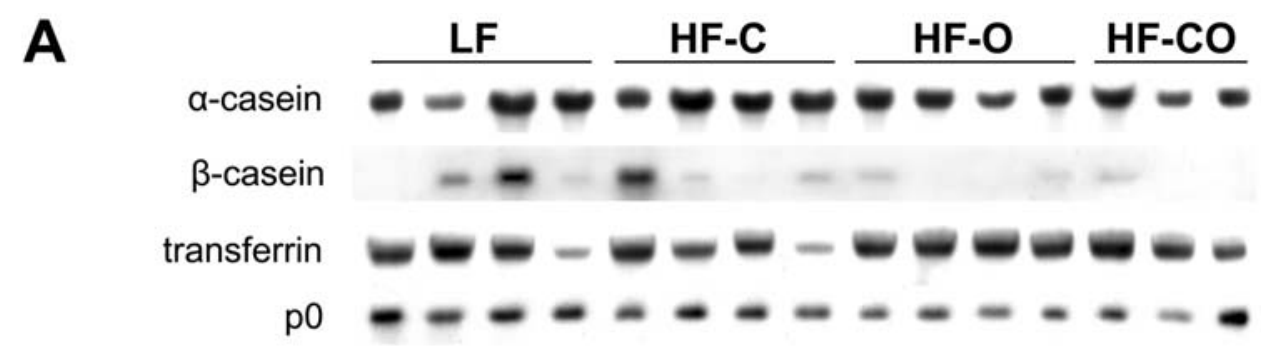

B
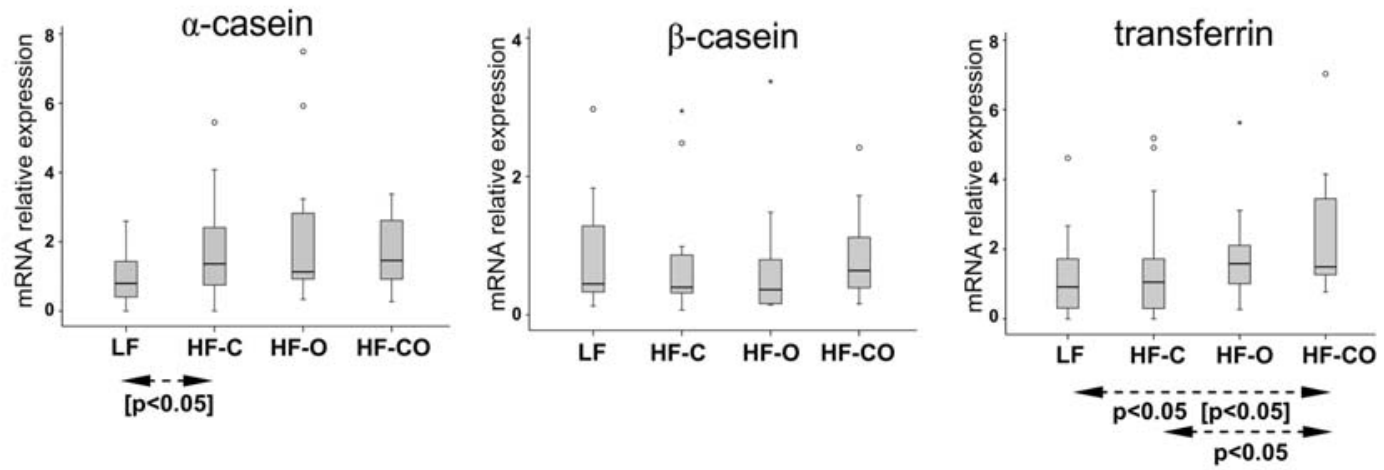

Figure 1. Effects of a high corn oil diet and a high olive oil diet on the expression of differentiation-associated genes in DMBA-induced mammary tumors. (A) Northern blot analyses of $\alpha$-casein, $B$-casein, transferrin and the control transcript p0 in the mammary tumors of rats fed the control diet (LF), high corn oil diet (HF-C), high olive oil diet (HF-O) and both high fat diets (HF-CO). (B) Relative mRNA expression of each gene. The box plot represents the interquartile range (25-75th percentile) and the line within this box is the median value. Bottom and top bars of the whisker indicate the 10th and 90 th percentiles, respectively. Outlier values are also represented. Tumors analyzed: 17 (LF), 22 (HF-C), 17 (HF-O) and 14 (HF-CO). Significance outside the brackets is related to the quantitative analysis; significance inside the brackets is related to the qualitative analysis.

was used as an endogenous control to normalize each sample and values were represented as mRNA relative abundance.

Western blot analysis. Tumor-frozen tissues were homogenized in a buffer containing $50 \mathrm{mM}$ Tris- $\mathrm{HCl} \mathrm{pH} 7.2,250 \mathrm{mM}$ sucrose, $2 \mathrm{mM}$ EDTA, $1 \mathrm{mM}$ EGTA, $5 \mathrm{mM} \mathrm{MgCl}_{2}, 50 \mu \mathrm{M}$ $\mathrm{NaF}, 100 \mu \mathrm{M} \mathrm{Na} \mathrm{VO}_{4}, 10 \mu \mathrm{l} / \mathrm{ml}$ protease inhibitor cocktail (Sigma-Aldrich), $10 \mathrm{mM} \beta$-mercaptoethanol and 1\% Triton $\mathrm{X}-100$. Protein concentration was determined by the Lowry method. Samples were separated in two replicates, one for Western blot analysis and the other for a later verification of the quantity of protein loaded. Tumor extracts $(15 \mu \mathrm{g})$ were subjected to SDS-PAGE on a $10 \%$ acrylamide gel followed by eletrophoretic blotting onto PVDF membranes (Hybond-P, GE Healthcare). The membranes were initially incubated for $10 \mathrm{~min}$ in Tris-buffered saline with Tween-20 (TBS-T: $20 \mathrm{mM}$ Tris- $\mathrm{HCl} \mathrm{pH}$ 7.6, $137 \mathrm{mM} \mathrm{NaCl}, 1 \%$ Tween-20) and pre-incubated overnight with $5 \%$ nonfat dry milk to block non-specific binding. Subsequently, the membranes were incubated for $2 \mathrm{~h}$ at room temperature in the presence of the specific antibody: $\beta$-actin (clone AC-15, Sigma-Aldrich), used at 1:15000 dilution; or ZBP1, kindly provided by Dr S. Hüttelmaier (23), used at 1:5000 dilution. The membranes were washed with TBS-T, incubated with horseradish peroxidase-labeled secondary antibody (Sigma-Aldrich) for $1 \mathrm{~h}$ at room temperature and washed again with TBS-T. Antibody binding sites were visualized on Hyperfilm using the Amersham ECL ${ }^{\mathrm{TM}}$ Western blot detection system (GE Healthcare) according to the manufacturer's instructions. We used three replicates of a control sample in each Western blot to compare the different blots. The specific densitometric value of each sample was analyzed using Quantity One software (Bio-Rad Laboratories) and values were first normalized relative to $\mu \mathrm{g}$ of protein loaded and then relative to the mean of the three replicates of the control sample.

Statistical methods. Statistical analyses were performed with SPSS software. Since data did not follow a normal distribution and variances were heterogeneous, quantitative data were analyzed with the non-parametric Mann-Whitney $\mathrm{U}$ test. mRNA expression values were also analyzed qualitatively calculating the percentage of tumors in each group with a relative abundance higher than the median of the control group. Qualitative data were analyzed through the $\chi^{2}$ test. Then, the non-parametric correlations were carried out through Kendall's tau-b and Spearman's rho tests. The level of significance was established at $\mathrm{p}<0.05$.

\section{Results}

Gene expression of differentiation markers. The mRNA levels for the mammary differentiation biomarkers $\alpha$-casein, $\beta$-casein and transferrin were determined by Northern blot analyses (Fig. 1A). In each case, the size of the mRNAs detected was in accordance to those previously described. The expression levels of $\alpha$-casein were significantly higher than those of $\beta$ casein in the mammary adenocarcinomas from all the experimental groups. The level of $\alpha$-casein was slightly higher in all high fat groups related to the low fat group, though the 
Table I. Composition of experimental diets $(\mathrm{g} / \mathrm{kg})$.

\begin{tabular}{lccc}
\hline & Low fat & $\begin{array}{c}\text { High fat } \\
\text { corn oil }\end{array}$ & $\begin{array}{c}\text { High fat } \\
\text { olive oil }\end{array}$ \\
\hline Proteins (casein) & 180 & 230 & 230 \\
Carbohydrates (dextrose) & 679 & 459 & 459 \\
Lipids & & & \\
$\quad$ Corn oil & 30 & 200 & 30 \\
Extra virgin olive oil & 0 & 0 & 170 \\
Fiber (cellulose) & 50 & 50 & 50 \\
Salt mix & 59 & 59 & 59 \\
Vitamin mix & 2.4 & 2.4 & 2.4 \\
\hline
\end{tabular}

changes observed were not quantitatively significant; only the difference between LF and HF-O was close to a statistical significance $(\mathrm{p}<0.1)$. In addition, the percentage of tumors with higher values than the median of the control group (qualitative analysis) was close to significance in the HF-O group $(12 / 17,70.6 \%, \mathrm{p}<0.1)$ and statistically significant in the HF-C group $(16 / 21,76.2 \%, \mathrm{p}<0.05)$ (Fig. 1B). When we analyzed the expression of $B$-casein we found that not all tumors have detectable levels of this transcript. We did not find significant differences in the percentage of tumors displaying $\beta$-casein mRNA: $52.4 \%$ (11/21) in LF, 72.7\% (16/22) in HF-C, 58.8\% (10/17) in HF-O, and 68.6\% (11/16) in $\mathrm{HF}-\mathrm{CO}$. In the adenocarcinomas with a detectable expression of $B$-casein, there were no differences in the mRNA levels due to the experimental diets (Fig. 1B).

Transferrin mRNA expression was similar in groups LF and HF-C, while the high olive oil groups had higher values than the control and high corn oil groups (Fig. 1B). These differences were quantitatively significant for group HF-CO. In addition, the qualitative analysis showed a significant percentage of tumors with higher values for transferrin than the median of the control in HF-CO and close to a significance in HF-O. Thus, $75.0 \%$ of the tumors from the HF-O group and $100 \%$ of the tumors from the HF-CO group had higher transferrin mRNA levels than the median expression of the control group.

$\beta$-actin mRNA and protein expression. The mRNA of $B$-actin was detected by Northern blot in each of the tumors analyzed. The $B$-actin relative expression levels were slightly higher in the tumors from the animals fed the high fat diets (Fig. 2A), showing the trend to be significant when LF and HF-O were compared. The percentage of tumors with a higher expression than the median of control was significantly high in the HF-C group. Thus, we further analyzed the expression of $\beta$-actin by determination of the protein levels. Western blot analyses of total extracts from tumor tissues did not show differences due to the experimental diets (Fig. 2B). Moreover, when we correlated the results obtained in each tumor, we observed that the mRNA and protein levels of $\beta$-actin did not have a statistically significant correlation.
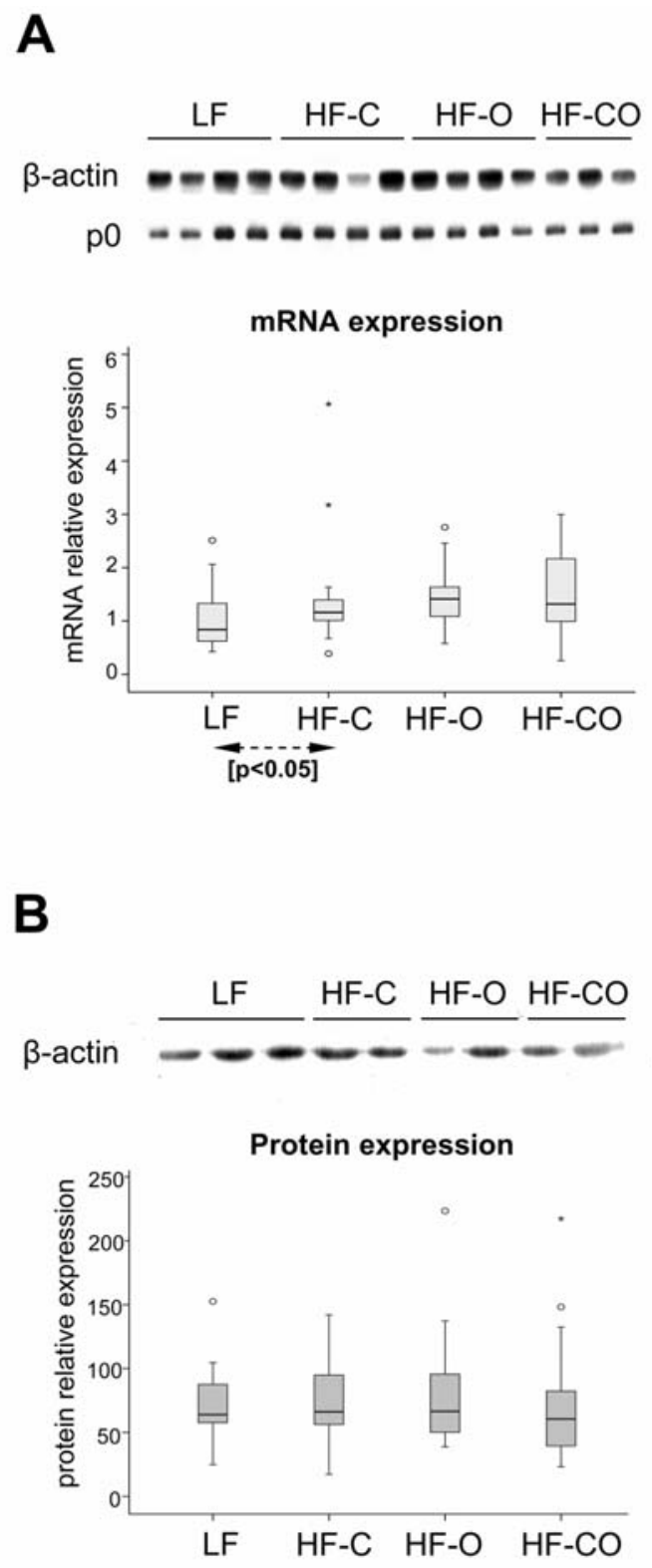

Figure 2. Effects of the experimental diets on the expression of $B$-actin in DMBA-induced mammary tumors. (A) Northern blot analyses for B-actin showed an increase of the mRNA relative expression in the HF-C and HF-O groups. (B) Western blot analyses of the protein B-actin did not show differences among the groups. Tumors analyzed: 18 (LF), 22 (HF-C), 17 (HF-O) and 16 (HF-CO). Significance inside the brackets is related to the qualitative analysis.

ZBP1 expression. Since we observed changes in the $\beta$-actin mRNA levels by effect of the diets, though such changes were not accompanied by increases in the protein expression, we analyzed the protein levels of ZBP1, the B-actin mRNA transporter. ZBP1 was analyzed by Western blot and the levels of this protein were significantly higher in the HF-C groups than in the control and HF-O groups (Fig. 3).

On the other hand, we found a significant positive correlation between the protein levels of $B$-actin and those of ZBP1 in the control group (Kendall's tau-b $\mathrm{R}=0.410, \mathrm{P}=0.05$; Spearman's rho $\mathrm{R}=0.588, \mathrm{p}<0.05)$. However, this correlation was not maintained in the three groups fed the high fat diets. 

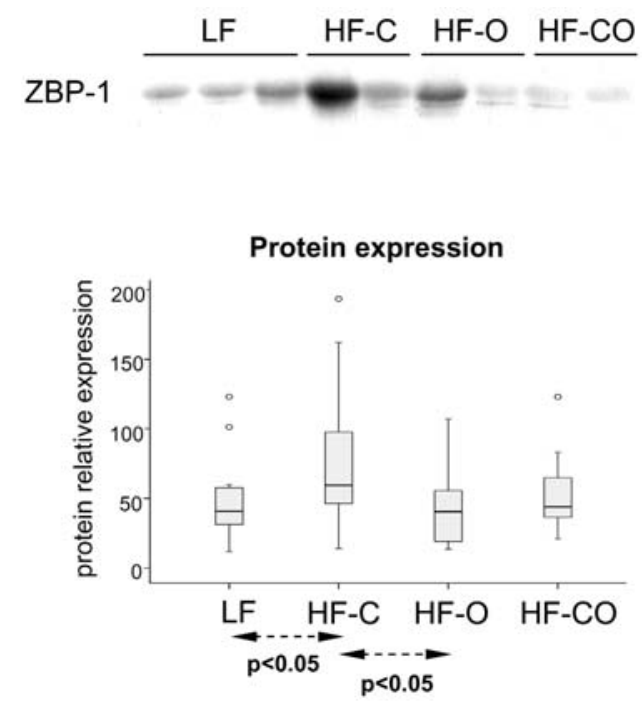

Figure 3. Effects of the experimental diets on the expression of ZBP1 in DMBA-induced mammary tumors. Western blot analyses of the transporter ZBP1 indicated an increased expression of this protein in the high corn oil group (HF-C). Tumors analyzed: 12 (LF), 17 (HF-C), 13 (HF-O) and 16 (HF-CO). Significance is related to the quantitative analysis.

\section{Discussion}

Cancer is influenced by many environmental factors, which can modify the promotion of tumors. In previous studies in vivo we found that high fat diets had a clear effect on the morphological differentiation and clinical degree of malignancy of experimental tumors, which was accompanied by modifications in genes related to proliferation and differentiation. In this study, we are aiming to further characterize the influence of different dietary lipids on the expression of differentiation genes, including classic biomarkers of mammary differentiation. Herein, we described that the expression of the $\alpha$ - and $\beta$-caseins was not related to the degree of morphological differentiation nor to the clinical behavior, which suggests that these genes were not good biomarkers of the modifications that the experimental diets conferred to the adenocarcinomas. On the contrary, a high olive oil diet and a high corn oil diet induced different modifications in the expression of transferrin as well as in the ZBP1 protein, which can be related to the tumor-enhancing effect of the high corn oil and the possible tumor-protective effect of the high olive oil diet, which we described $(7,9,31)$. Moreover, these high fat diets may have an effect on the translation of $\beta$-actin from mRNA to protein, a process in which ZBP1 has an important role.

We previously demonstrated that a diet rich in n-6 polyunsaturated fatty acids (high corn oil diet) clearly exerted a stimulating effect on DMBA-induced breast cancer. In contrast, a high extra virgin olive oil diet conferred to the mammary tumors a less aggressive behavior and less morphological dedifferentiation $(7,9,31)$. To gain insight into the molecular changes that are related to the tumor phenotypes induced by the high fat diets, the mRNA expression levels of differentiation-related genes were analyzed in the adenocarcinomas from the different experimental groups. The $\alpha$ - and $\beta$-caseins are considered markers of the differentiation of the mammary gland (32). Caseins are down-regulated in rat mammary tumors induced with several carcinogens, including DMBA, in comparison with the normal mammary tissue $(18,19,32)$. In the literature there is little data regarding the effects of dietary lipids on the expression of caseins. Linoleic and oleic acids modulated casein accumulation in rat mammary epithelial cells in a time-, hormone- and dose-dependent manner (33). In PhIP mammary tumors, $B$-casein expression was increased in the animals which were fed a high linoleic acid diet (18). Such results were postulated to be due to an increase in the serum prolactin levels that the dietary lipid could be inducing. However, increases in serum prolactin due to the effect of high fat diets have been previously attributed to conditions of ether stress (34). Nevertheless, the animals used in this study were euthanized by troncular decapitation and did not undergo an ether stress condition. Thus, despite the relationship that we had found between the high fat diets and differentiation, in our studies the lipids did not modify the expression of the $\alpha$ - and $\beta$-caseins, indicating that in DMBA-induced mammary tumors, unlike the normal mammary gland, the expression of these genes would not be a good indicator of the degree of morphological differentiation.

Transferrin is the major iron binding protein in the rat mammary gland, although this protein can have other functions in growth regulation and differentiation in the gland $(16,35)$. It appears to play a role in the mechanisms through which estrogens favor mammary-gland development in rats (36). Transferrin expression decreases in chemically-induced mammary carcinomas $(18,19)$. This gene was of interest as it has a different regulation from caseins, since it is relatively insensitive in vitro to the lactogenic hormones that regulate casein expression $(16,35)$. In DMBA experimental tumors, we found that the high corn oil diet did not modify the mRNA content of this gene, while in the high olive oil fed groups, particularly HF-CO, transferrin mRNA expression was increased. Our results are in accordance with the less aggressive behavior of the tumors due to the effect of the high extra virgin olive oil diet previously reported $(7,9,31)$. In this way, some of the clinical parameters used to characterize the behavior of the tumors were compatible with a protective effect of the high olive oil diet. Thus, the group of animals that were fed this diet had longer tumor latency time and a lower total number of tumors, number of tumors per animal and tumor volume than the low fat control group (9).

We analyzed the expression of $\beta$-actin, a cytoskeletal protein that has long been used as a housekeeping gene. However, the expression of this gene has been associated with dedifferentiation and with motility capacity $(20,21)$. B-actin mRNA and protein levels have also been observed to increase during mammary gland involution and decrease during lactation (37). Moreover, a hint for investigating if the effects of high fat diets were associated to changes in B-actin came from our previous observations, where we found that $\beta$-actin could not be used as a control gene since its expression greatly changed among the tumor samples. In this study, we observed higher levels of $\beta$-actin mRNA in the high fat groups, close to significance, in accordance with previous studies where the high corn oil diet significantly increased the expression of that gene (unpublished data). On the contrary, 
B-actin protein levels were not modified in any experimental condition. These results suggested that dietary lipids can be affecting the translation from mRNA to protein. Such a process has importance in tumor cells, as it has been observed that the acquisition of metastatic potential is related to the localization of $B$-actin mRNA in the cellular edge before being translated (21). In the literature, there is inconsistent data regarding the effects of dietary lipids on $\beta$-actin expression. In isolated rat hepatocytes, the polyunsaturated arachidonic acid (20:4 n-6) induced the up-regulation of $\beta$-actin mRNA, whereas monounsaturated eicosanoic acid (20:1 n-9) had no effect (38). $\beta$-actin mRNA was unchanged in the jejunum of rats fed a diet rich in long-chain triacylglycerols (39), while in the pancreas $\beta$-actin expression decreased due to the effect of $17.4 \%$ PUFA or saturated fatty acid diets in comparison to a low fat diet (40). In hepatoma cells grown in rats, linoleic acid- and linolenic acid-enriched diets induced a decrease of $\beta$-actin in the tumor cells (41). Thus, the disparity of results reported in the bibliography suggests a tissue-specific effect of dietary lipids.

To further investigate the effect that the high fat diets may be exerting in the translational process of $\beta$-actin, we analyzed the ZBP1 protein. This protein binds specifically to $\beta$-actin mRNA and transports the transcript from the nucleus to the periphery of the cell (22). We observed an increase in $\mathrm{ZBP} 1$ in the high corn oil group related to the control and high olive oil groups. When we studied the expression levels of the $\beta$-actin protein in relation to the ZBP1 protein, we found a positive correlation in the control group, though not in the high fat groups. Such results support the hypothesis that the high fat diets can be affecting B-actin mRNA transport and translation. In this sense, some lipids are important in the regulation of the function of the nuclear membrane. Changes in the activity of nucleotide-triphosphatase due to the effect of linoleic acid have been described, which can produce alterations in the RNA flux from the nucleus to the cytoplasm (42). Lipids can also affect the membrane fluidity and thus the proteins with a role in the transduction pathways from the membranes (42-44). Notably, a significant increase in ZBP1 protein levels has been observed in the tumors with the most aggressive degree of malignancy, those of the group fed the high corn oil diet. ZBP1, also known as CRD-BR or IMP1, seems to be an oncofetal protein and has been linked to carcinogenesis, including in human breast tumors (24). In relation to this, transgenic mice overexpressing ZBP1 developed mammary tumors, which suggested that it is a proto-oncogene (25). All this evidence suggests that the increase in ZBP1 expression that was found can be related to the higher degree of malignancy of the tumors from the animals fed the HF-C diet. Those tumors appeared earlier and were less differentiated, displaying a higher architectural and nuclear degree and a high mitotic activity. Additionally, the high corn oil diet induced more tumor-bearing animals, the total number of tumors, the number of tumors per animal and tumor volume, in relation to the control and high olive oil diets (9). Furthermore, ZBP1 is a transporter of other RNAs, such as the H19 non-coding RNA. H19 is an imprinted gene with a controversial role, as tumor-suppressing or tumorpromoting properties have been reported (45-47). Notably, we previously found a significant down-modulation of H19 in the HF-C group, though no changes in the groups fed the high olive oil diets were observed $(7,13)$.

In conclusion, our study revealed that the high olive oil and the high corn oil diets induce different changes in the expression of the differentiation-related genes transferrin and ZBP1, compatible with the different modulatory effects of these diets in experimental breast cancer (a tumor-enhancing effect of the high corn oil diet and a protective effect of the high extra virgin olive oil diet). These results suggest that modifications in the mRNA and protein expression of these kinds of genes can be one of the mechanisms by which the lipids of the diet can be exerting these modulatory effects. Moreover, caseins are not good biomarkers of differentiation in this in vivo model, thus they do not reflect the changes in differentiation features that these dietary lipids confer in the mammary adenocarcinomas.

\section{Acknowledgements}

This study was supported by grants from 'Plan Nacional de I+D+I 2000-2003' and FEDER (BFI 2003-07341); and from 'Plan Nacional de I+D+I 2004-2007' and FEDER (AGL200607691/ALI); and from 'Fundación Patrimonio Comunal Olivarero 2008-2012' (FPCO2008-165396). Laura Grau has a Pre-doctorate scholarship from 'Departament d'Universitats, Recerca i Societat de la Informació de la Generalitat de Catalunya i del Fons Social Europeu'.

\section{References}

1. Jemal A, Siegel R, Ward E, Murray T, Xu J and Thun MJ: Cancer statistics, 2007. CA Cancer J Clin 57: 43-66, 2007.

2. WCRF/AICR World Cancer Research Fund and American Institute for Cancer Research: Food, Nutrition and the Prevention of Cancer: a Global Perspective. American Institute for Cancer Research, Washington DC, 1997.

3. Bartsch H, Nair J and Owen RW: Dietary polyunsaturated fatty acids and cancers of the breast and colorectum: emerging evidence for their role as risk modifiers. Carcinogenesis 26: 2209-2218, 1999.

4. Ip C: Fat and essential fatty acid in mammary carcinogenesis. Am J Clin Nutr 45: S218-S224, 1987.

5. Ip C: Review of the effects of trans fatty acids, oleic acid, n-3 polyunsaturated fatty acids, and conjugated linoleic acid on mammary carcinogenesis in animals. Am J Clin Nutr 66: 1523S-1529S, 1997.

6. Kolonel LN, Nomura AM and Cooney RV: Dietary fat and prostate cancer: current status. J Natl Cancer Inst 91: 414-428, 1999.

7. Escrich E, Solanas M and Moral R: Olive oil, and other dietary lipids, in cancer: experimental approaches. In: Olive Oil and Health. Quiles JL, Ramírez-Tortosa MC and Yaqoob P (eds). CAB International, Oxfordshire, pp317-374, 2006.

8. Trichopoulou A, Lagiou P, Kuper H and Trichopoulos D: Cancer and Mediterranean dietary traditions. Cancer Epidemiol Biomarkers Prev 9: 869-873, 2000.

9. Solanas M, Hurtado A, Costa C, Moral R, Menéndez JA, Colomer R and Escrich E: Effects of a high olive oil diet on the clinical behavior and histopathological features of rat DMBAinduced mammary tumors compared with a high corn oil diet. Int J Oncol 21: 745-753, 2002.

10. Costa I, Moral R, Solanas M and Escrich E: High-fat corn oil diet promotes the development of high histologic grade rat DMBA-induced mammary adenocarcinomas, while high olive oil diet does not. Breast Cancer Res Treat 86: 225-235, 2004.

11. Moral R, Solanas M, Garcia G, Colomer R and Escrich E: Modulation of EGFR and neu expression by n- 6 and n- 9 high-fat diets in experimental mammary adenocarcinomas. Oncol Rep 10: 1417-1424, 2003. 
12. Solanas M, Moral R and Escrich E: The stimulating effect of a high-fat $n-6$ polyunsaturated diet on rat DMBA-induced mammary tumors is not related to changes in c-Ha-ras $1 \mathrm{mRNA}$ tumor expression. Nutr Res 21: 1261-1273, 2001.

13. Escrich E, Moral R, García G, Costa I, Sánchez JA and Solanas M: Identification of novel differentially expressed genes by the effect of a high-fat n- 6 diet in experimental breast cancer. Mol Carcinog 40: 73-78, 2004.

14. Solanas M, Escrich E, Rouzaut A, Costa I, Martinez A and Notario V: Deregulated expression of the PCPH proto-oncogene in rat mammary tumors induced with 7,12-dimethylbenz[a] anthracene. Mol Carcinog 33: 219-227, 2002.

15. Johnson ML, Levy J and Rosen JM: Isolation and characterization of casein-producing and -nonproducing cell populations from 7,12-dimethylbenz(a)anthracene-induced rat mammary carcinomas. Cancer Res 43: 2199-2209, 1983.

16. Chen LH and Bissell MJ: Transferrin mRNA level in the mouse mammary gland is regulated by pregnancy and extracellular matrix. Biol Chem 262: 17247-17250, 1987.

17. Papaconstantinou AD, Shanmugam I, Shan L, Schroeder IS, Qiu C, Yu M and Snyderwine EG: Gene expression profiling in the mammary gland of rats treated with 7,12-dimethylbenz[a] anthracene. Int J Cancer 118: 17-24, 2006.

18. Roberts-Thomson SJ and Snyderwine EG: mRNA differential display of 2-amino-1-mehtyl-6-phenylimidazo [4, 5-b]pyridineinduced rat mammary gland tumors. Breast Cancer Res Treat 51: 99-107, 1998

19. Shan L, Yu M and Snyderwine EG: Global gene expression profiling of chemically induced rat mammary gland carcinomas and adenomas. Toxicol Pathol 33: 768-775, 2005.

20. Reid LM, Narita M, Fujita M, Murray Z, Liverpool C and Rosenberg L: Matrix and hormonal regulation of differentiation in liver cultures. In: Research in isolated and cultured hepatocytes. Guillouzo A, Guguen-Guillouzo C (eds). John Libbey Eurotext Ltd Inserm, London, pp225-258, 1986.

21. Shestakova EA, Wyckoff J, Jones J, Singer RH and Condeelis J: Correlation of beta-actin messenger RNA localization with metastatic potential in rat adenocarcinoma cell lines. Cancer Res 59: 1202-1205, 1999.

22. Oleynikov Y and Singer RH: Real-time visualization of ZBP1 association with beta-actin mRNA during transcription and localization. Curr Biol 13: 199-207, 2003.

23. Hüttelmaier S, Zenklusen D, Lederer M, Dictenberg J, Lorenz M, Meng X, Bassell GJ, Condeelis J and Singer RH: Spatial regulation of beta-actin translation by Src-dependent phosphorylation of ZBP1. Nature 438: 432-435, 2005.

24. Ioannidis P, Mahaira L, Papadopoulou A, Teixeira MR, Heim S, Andersen JA, Evangelou E, Dafni U, Pandis N and Trangas T: CRD-BP: a c-Myc mRNA stabilizing protein with an oncofetal pattern of expression. Anticancer Res 23: 2179-2183, 2003.

25. Tessier CR, Doyle GA, Clark BA, Pitot HC and Ross J: Mammary tumor induction in transgenic mice expressing an RNA-binding protein. Cancer Res 64: 209-214, 2004.

26. Escrich E, Solanas M and Segura R: Experimental diets for the study of lipid influence on induced mammary carcinoma in rats: I - Diet definition. In Vivo 8: 1099-1106, 1994.

27. Escrich E, Solanas M, Ruiz de Villa MC, Ribalta T, Muntane J and Segura R: Experimental diets for the study of lipid influence on induced mammary carcinoma in rats: II - Suitability of the diets. In Vivo 8: 1107-1112, 1994.

28. Solanas M, Moral R and Escrich E: Improved nonradioactive Northern blot protocol for detecting low abundance mRNAs from mammalian tissues. Biotechnol Lett 23: 263-266, 2001.

29. Alonso S, Minty A, Bourlet Y and Buckingham M: Comparison of three actin-coding sequences in the mouse; evolutionary relationships between the actin genes of warm-blooded vertebrates. J Mol Evol 23: 11-22, 1986.

30. Wool IG, Chan YL, Glück A and Suzuki K: The primary structure of rat ribosomal proteins $\mathrm{P} 0, \mathrm{P} 1$ and $\mathrm{P} 2$ and a proposal for a uniform nomenclature for mammalian and yeast ribosomal proteins. Biochimie 73: 861-870, 1991.
31. Escrich E, Moral R, Grau L, Costa I and Solanas M: Molecular mechanisms of the effects of olive oil and other dietary lipids on cancer. Mol Nutr Food Res 51: 1279-1292, 2007.

32. Supowit SC and Rosen JM: Hormonal induction of casein gene expression limited to a small subpopulation of 7,12-dimethylbenz (a)anthracene-induced mammary tumor cells. Cancer Res 42: 1355-1360, 1982.

33. Sigurdson SL and Ip MM: Casein accumulation by rat mammary epithelial cells grown within a reconstituted basement membrane is modulated by fatty acids in a hormone- and time-dependent manner. Exp Cell Res 208: 333-343, 1993.

34. Bosland MC, Bunnik GS, Wilbrink B, de Bie BT and Floor B: Dietary fat affects plasma prolactin in female F344 rats under conditions of ether stress. Nutr Cancer 22: 247-256, 1994.

35. Lee EY, Barcellos-Hoff MH, Chen LH, Parry G and Bissell MJ: Transferrin is a major mouse milk protein and is synthesized by mammary epithelial cells. In Vitro Cell Dev Biol 23: 221-226, 1987.

36. Escalante R, Houdebine LM and Pamblanco M: Transferrin gene expression in the mammary gland of the rat. The enhancing effect of 17 beta-oestradiol on the level of RNA is tissue-specific. J Mol Endocrinol 11: 151-159, 1993.

37. Wiens DJ, Brooks CL and Hodgson CP: Casein, actin, and tubulin expression during early involution in bovine and murine mammary tissue. J Dairy Sci 75: 1857-1869, 1992.

38. Armstrong MK, Blake WL and Clarke SD: Arachidonic acid suppression of fatty acid synthase gene expression in cultured rat hepatocytes. Biochem Biophys Res Commun 177: 1056-1061, 1991.

39. Suruga K, Suzuki R, Goda $T$ and Takase S: Unsaturated fatty acids regulate gene expression of cellular retinol-binding protein, type II in rat jejunum. J Nutr 125: 2039-2044, 1995.

40. Ricketts $J$ and Brannon PM: Amount and type of dietary fat regulate pancreatic lipase gene expression in rats. J Nutr 124: 1166-1171, 1994.

41. Vecchini A, Ceccarelli V, Nocentini G, Riccardi C, Di Nardo P and Binaglia L: Dietary PUFA modulate the expression of proliferation and differentiation markers in Morris 3924A hepatoma cells. Biochim Biophys Acta 1737: 138-144, 2005.

42. Clandinin MT, Cheema S, Field CJ, Garg ML, Venkatraman J and Clandinin TR: Dietary fat: exogenous determination of membrane structure and cell function. FASEB J 5: 2761-2769, 1991.

43. Escrich E, Solanas M, Soler M, Ruiz de Villa MC, Sanchez JA and Segura R: Dietary polyunsaturated n-6 lipids effects on the growth and fatty acid composition of rat mammary tumors. J Nutr Biochem 12: 536-549, 2001.

44. Dowhan W, Mileykovskaya E and Bogdanov M: Diversity and versatility of lipid-protein interactions revealed by molecular genetic approaches. Biochim Biophys Acta 1666: 19-39, 2004.

45. Looijenga LH, Verkerk AJ, De Groot N, Hochberg AA and Oosterhuis JW: H19 in normal development and neoplasia. Mol Reprod Dev 46: 419-439, 1997.

46. Adriaenssens E, Lottin S, Berteaux N, Hornez L, Fauquette W, Fafeur V, Peyrat JP, Le Bourhis X, Hondermarck H, Coll J, Dugimont $\mathrm{T}$ and Curgy JJ: Cross-talk between mesenchyme and epithelium increases $\mathrm{H} 19$ gene expression during scattering and morphogenesis of epithelial cells. Exp Cell Res 275: 215-229, 2002.

47. Berteaux N, Lottin S, Monte D, Pinte S, Quatannens B, Coll J, Hondermarck H, Curgy JJ, Dugimont T and Adriaenssens E: H19 mRNA-like noncoding RNA promotes breast cancer cell proliferation through positive control by E2F1. J Biol Chem 280: 29625-29636, 2005. 